\title{
Length-tension relationship of the posterior deltoid to triceps transfer in C6 tetraplegic patients
}

\author{
E Rabischong $\mathrm{PhD},{ }^{1,2} \mathrm{P}$ Benoit $\mathrm{PT},{ }^{2} \mathrm{M}$ Benichou MD, ${ }^{2} \mathrm{Y}$ Allieu $\mathrm{MD}^{3}$ \\ ${ }^{I}$ INSERM U 103, Appareil Moteur et Handicap, 395 Avenue des Moulins, 34090 \\ Montpellier; ${ }^{2}$ Centre PROPARA, 263 Rue du caducée, Parc Euromédecine, 34090 \\ Montpellier; ${ }^{3}$ Service de Chirurgie Orthopédique, Hopital LAPEYRONIE, Route de \\ Ganges, 34090 Montpellier, France.
}

\begin{abstract}
We assessed the length-tension relationship of the posterior deltoid to triceps transfer in 8 tetraplegics $(n=11$ transfers) and compared the results to the length-tension relationship of the normal triceps measured in a check sample composed of 9 able bodied, right handed women. We designed a device to lock the arm and forearm and used a force transducer to assess the torque output isometrically. The muscle was tested at 6 different lengths $(130,110,90,70,45$ and $0^{\circ}$ of elbow flexion) with the shoulder abducted at $90^{\circ}$. As expected, the transfer behaved differently from the normal triceps. The mean maximum torque recorded was $7.8 \mathrm{Nm}$ in patients while it was $27 \mathrm{Nm}$ in the check sample. When compared, the absolute values (ie values expressed with a dimension of torque) were significantly different between groups $(0.00001<p<0.002)$. The expression of this relation (ie the relative values expressed as percentage of maximum values) revealed significant statistical differences $(p<0.002)$ at 90 and $70^{\circ}$ of elbow flexion; the peak torque was recorded at $130^{\circ}$ in patients while it was recorded at $110^{\circ}$ in the check sample, with a plateau between $110^{\circ}$ and $70^{\circ}$. On the other hand, if the length-tension relationship was fairly similar among subjects of the check sample, it exhibited tremendous differences among patients; it seemed that initial tension given by the surgeon represented a variable difficult to control without a device dedicated to that task.
\end{abstract}

Keywords: length-tension relationship; tendon transfer; torque output; tetraplegics.

\section{Introduction}

Posterior deltoid to triceps transfer represents a well known technique to reconstruct elbow extension in C6 complete tetraplegics since Moberg introduced the method. ${ }^{1}$ However, the original technique was modified by several authors. Dacron, tendon of the tibialis anterior, fascia lata or toe extensor tendon could be used as a mechanical interface to connect the active posterior deltoid and the triceps tendon. . $^{2,3}$

On the other hand, the transfer represents merely a part of the deltoid muscle and, therefore, its torque output is limited. The aim of the study was to record the length-tension relationship of the transfer and compare with the normal triceps. Fin- ally, the surgical technique will be discussed.

\section{Material and methods}

\section{Population}

We studied 2 groups. The first was composed of 8 tetraplegic patients for a total of 11 posterior deltoids to triceps transfers (3 patients with a bilateral transfer). All the spinal cord injured patients had complete lesion in C6 (Table I). The mean age was $33.6( \pm 8.2)$. The time after injury was fairly extended from 28 to 173 months with a mean value of 88.5 months. The time before surgery was also extended with a mean time of 34.5 months but with a very large standard deviation (45.4). When patient 7 
Table I Data concerning the group of patients

\begin{tabular}{cccccc}
\hline Subject & Side & Age & $\begin{array}{c}\text { Delay (months) } \\
\text { After } \\
\text { injury }\end{array}$ & $\begin{array}{c}\text { Before } \\
\text { surgery }\end{array}$ & $\begin{array}{c}\text { After } \\
\text { surgery }\end{array}$ \\
\hline 1 & Right & 32 & 28 & 18 & 10 \\
2 & Left & & & 15 & 13 \\
3 & Left & 30 & 110 & 38 & 72 \\
& Right & 29 & 111 & 39 & 84 \\
4 & Left & & & 27 & 96 \\
5 & Right & 52 & 110 & 14 & 26 \\
& Right & 34 & 39 & 13 & 25 \\
6 & Left & & & 10 & 5 \\
7 & Left & 35 & 39 & 14 & 75 \\
8 & Left & 33 & 173 & 168 & 46.1 \\
\hline Average & Right & 24 & 98 & 23 & 33.7 \\
SD & & 33.6 & 88.5 & 34.5 & 45.4 \\
\hline
\end{tabular}

$\mathrm{SD}=$ standard deviation

was excluded, the mean time became 21.1 months $( \pm 10.4)$. To be assessed the patient had to be trained with the authorisation of active contraction in the complete range of motion; therefore, the time after surgery could not be less than 2 months. This time was 46.1 months on average (extremes from 5 to 96 months). Concerning the surgical technique, the interface between the muscle and the tendon was created with dacron wrapped with fascia lata in each patient. During surgery the transfer was maximally stretched with the elbow fully extended $\left(0^{\circ}\right)$. After surgery the upper limb remained fixed in a splint with the shoulder abducted at $90^{\circ}$ and the elbow at $0^{\circ}$. This immobilisation was strictly maintained for 3 weeks. Then, the rehabilitation technique had to increase the range of motion of the elbow in steps of $20^{\circ}$ per week over 6 weeks. The work was always active without any resistance before the sixth week. During this period, the abduction was reduced at $45^{\circ}$ degrees (end of the fourth week), then 20 to $30^{\circ}$ (end of the 5 th week) to $0^{\circ}$. The splint was maintained for 8 weeks.

A second group was composed of 9 right handed women with a mean age of 29.5 $( \pm 3.6)$. The normal triceps was assessed in the same condition and with the same device as for the first group to obtain comparable data.

\section{Materials}

We designed a force transducer ${ }^{4}$ with strain gauges (Wheatstone bridge) placed in such a way that only axial efforts were measured (Fig 1). It was mounted on an axis enabling us to adjust it on the posterior aspect of the forearm. It was padded with stuffing. The bridge was supplied $( \pm 5 \mathrm{~V})$ and results were plotted after amplification (Sensormedics, Dynagraph Recorder R. 611), with a $30 \mathrm{~Hz}$ filtering. The sensitivity was $0.1 \mathrm{mV} / \mathrm{mm}(2.5 \mathrm{~N} / \mathrm{mm})$ and the transducer was calibrated before each set of measurements.

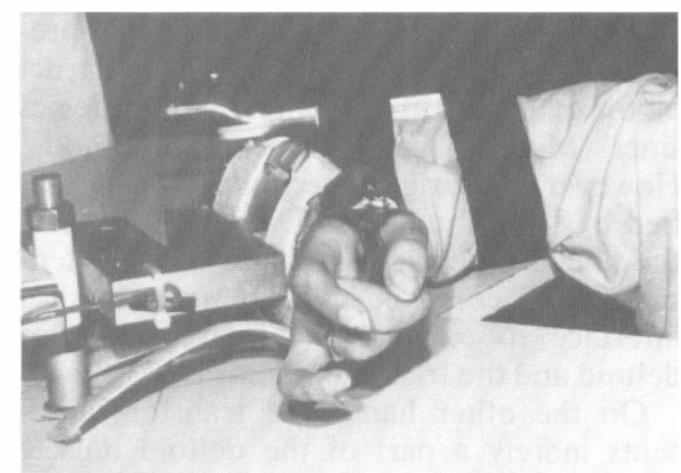

Figure 1 View of the device used for assessment. The arm was attached to a splint and the transducer was supporting the forearm. 
The patient was seated in a wheelchair and the shoulder was abducted at $90^{\circ}$ with the arm resting on a special table designed for the study (Fig 1). A splint was placed on the back of the arm that was attached to it with straps. The transducer supported the forearm that was firmly strapped in it; it could be placed in different positions enabling us to assess the isometric torque output at 6 different muscle lengths $(130,110,90$, 70,45 and $0^{\circ}$ of elbow flexion). As the lever arm was constant, isometric torque calculation was very simple: $I_{i}=V_{i} d$ where $I_{i}$ is the isometric torque at the length $\mathrm{i}, \mathrm{V}_{\mathrm{i}}$, the value measured by the transducer at this length; and $\mathrm{d}$ the distance from the force application point, ie the centre of the transducer, to the centre of rotation of the elbow. The subjects from both groups were asked to exert maximal effort against the transducer. This effort never exceeded 2 seconds. Two trials were carried out and mean value was used. One minute's rest was given before each position change to avoid effects of fatigue.

The statistical analysis of the data was performed on a compatible computer with Statgrafics 5.0 (Uniware). A one way analysis of variance was computed and confirmed by a Mann-Withney non parametric test; differences were considered significant when $p<0.05$. We have studied absolute values (those expressed with a torque dimension $[\mathrm{Nm}]$ ) and relative values (those expressed as a percentage of maximal values). In the summary statistic table, we used the coefficient of variation calculated as

$$
\left[\frac{\delta}{\overline{\mathrm{x}}}\right] \times 100=\left[\frac{S D}{\text { Mean }}\right] \times 100
$$

\section{Results}

Concerning the absolute value (Tables II, III, Fig 2), we have recorded a very different torque output among groups. In fact, the highest torque output was found in the group of able bodied subjects with a mean torque of $28.5 \mathrm{Nm}$. In the patients' group, the best performance was $7.8 \mathrm{Nm}$ on average, ie $27.3 \%$ of the previous one. Patient 3 exhibited the best performance for both groups. It was noticed that the coefficient of variation was really higher in tetraplegics (from 46.2 to $88.6 \%$ ). Here was a sign of important disparities in the results among patients. Minimal values were recorded at $0^{\circ}$ in both groups where the muscle was at its shortest length. In patients, this fact implied an incomplete lock of the elbow that was clinically verified. Therefore, the clinical muscle testing was not used since the total range of motion was not explored. Nevertheless, all the patients were able to extend the elbow with the arm placed laterally to the head. Length-tension relationship was measured by a linear regression in patients: At $=0.019 \mathrm{Ep}+5.16$, with $r=0.955$ and $p=0.003$, where At was the absolute torque expressed in $\mathrm{Nm}$, and Ep the elbow position, ie the transfer length; and by a non linear regression in the able bodied group: At $=13.38+0.29 \quad \mathrm{Ep}-$ $(0.039 \mathrm{Ep})^{2}$, with $r^{2}=0.95$.

The one-way analysis of variance showed two homogeneous groups with an extremely low probability for each position providing highly significant differences (Table I). When compared, the relative values revealed a different behaviour in torque production among the two groups (Tables III, IV, Fig 3). In fact, maximum value was recorded at $130^{\circ}$ of elbow flexion in patients, while it was recorded at $110^{\circ}$ in the able bodied group. Moreover, in the latter a plateau was maintained between 110 and $70^{\circ}$. Here again, coefficients of variation were superior in patients. Therefore, in patients the maximum torque was mostly found at the maximum length for the transfer (6 transfers out of 11), ie at $130^{\circ}$. Nevertheless, patient 5 exhibited an opposite behaviour in his two transfers; maximum torque was recorded at $130^{\circ}$ on the right side and at $0^{\circ}$ on the other side. This underlined the importance of the surgical technique and, obviously of the surgeon who was different in the last case. As for the absolute values of torque output, the curves were measured by linear regression in patients: $\mathrm{Rt}=0.28 \mathrm{Ep}+44$, with $r=0.95$ and $p=0.002$, where $\mathrm{Rt}$ was the relative torque and Ep the elbow position; and by a non linear regression in the able bodied group: $\mathrm{Rt}=44.1+1.01 \mathrm{Ep}-(0.074 \mathrm{Ep})^{2}$, with 
Table II Isometric torque output expressed in $\mathrm{Nm}$ at the different muscle lengths for the patients

\begin{tabular}{lcccccc}
\hline & \multicolumn{6}{c}{ Elbow position (degrees) } \\
& 130 & 110 & 90 & 70 & 45 & 0 \\
\hline $1 \mathrm{R}$ & 7.3 & 4.4 & 3.4 & 2.4 & 1.9 & 1.9 \\
$1 \mathrm{~L}$ & 6.8 & 5.3 & 3.9 & 3.9 & 2.4 & 1.9 \\
$2 \mathrm{R}$ & 6.8 & 6.8 & 7.3 & 11.2 & 13.1 & 9.7 \\
$3 \mathrm{R}$ & 15.5 & 18.0 & 14.6 & 12.6 & 11.7 & 8.3 \\
$3 \mathrm{~L}$ & 13.6 & 11.2 & 10.4 & 9.2 & 6.8 & 4.4 \\
$4 \mathrm{R}$ & 4.9 & 3.9 & 2.4 & 1.9 & 1.5 & 0.5 \\
$5 \mathrm{R}$ & 7.3 & 5.8 & 5.8 & 7.3 & 6.3 & 6.3 \\
$5 \mathrm{~L}$ & 6.3 & 7.3 & 7.3 & 8.3 & 13.6 & 14.6 \\
$6 \mathrm{~L}$ & 3.4 & 2.9 & 1.9 & 1.0 & 1.0 & 1.0 \\
$7 \mathrm{~L}$ & 5.8 & 7.8 & 5.3 & 2.9 & 3.8 & 0.5 \\
$8 \mathrm{R}$ & 8.3 & 10.7 & 10.2 & 7.8 & 7.8 & 8.3 \\
Average & 7.8 & 7.6 & 6.6 & 6.2 & 6.3 & 5.2 \\
SD & 3.6 & 4.3 & 3.9 & 4.0 & 4.7 & 4.6 \\
Std Er & 1.1 & 1.3 & 1.2 & 1.2 & 1.4 & 1.4 \\
Minimum & 3.4 & 2.9 & 1.9 & 1.0 & 1.0 & 0.5 \\
Maximum & 15.5 & 18.0 & 14.6 & 12.6 & 13.6 & 14.6 \\
Coeff var & 46.2 & 56.3 & 58.9 & 64.1 & 74.4 & 88.6 \\
ANOVA & 0.0001 & 0.00001 & 0.00001 & 0.00001 & 0.0005 & 0.002 \\
\hline
\end{tabular}

$\mathrm{SD}=$ standard deviation

Std $\mathrm{Er}=$ standard error

Coeff var = coefficient of variation

ANOVA $=$ one-way analysis of variance (expressing the $p$ values when absolute values of torque were compared between groups

Table III Isometric torque output expressed in $\mathrm{Nm}$ at the different muscle lengths for the able bodied group

\begin{tabular}{lrrrrrr}
\hline & \multicolumn{5}{c}{ Elbow position (degrees) } \\
& 130 & 110 & 90 & 70 & 45 & 0 \\
\hline $1 \mathrm{~L}$ & 18.0 & 30.0 & 28.0 & 30.0 & 26.0 & 16.0 \\
$2 \mathrm{R}$ & 44.0 & 46.0 & 42.0 & 40.0 & 38.0 & 20.0 \\
$3 \mathrm{R}$ & 39.8 & 31.1 & 35.9 & 35.9 & 33.0 & 18.5 \\
$4 \mathrm{R}$ & 14.7 & 16.5 & 18.5 & 20.0 & 16.5 & 9.7 \\
$5 \mathrm{R}$ & 14.0 & 18.0 & 22.0 & 22.0 & 26.0 & 24.0 \\
$6 \mathrm{R}$ & 26.0 & 32.0 & 30.0 & 34.0 & 22.0 & 16.0 \\
$7 \mathrm{R}$ & 24.3 & 27.2 & 27.2 & 19.4 & 12.6 & 5.8 \\
$8 \mathrm{R}$ & 20.4 & 28.2 & 29.1 & 27.2 & 19.4 & 6.8 \\
$9 \mathrm{R}$ & 26.2 & 27.1 & 17.5 & 23.3 & 1.5 & 8.7 \\
Average & 25.3 & 28.5 & 27.8 & 28.0 & 21.7 & 13.9 \\
SD & 10.5 & 8.6 & 7.9 & 7.4 & 10.9 & 6.4 \\
Std Er & 3.5 & 2.9 & 2.6 & 2.5 & 3.6 & 2.1 \\
Minimum & 14.0 & 16.5 & 17.5 & 19.4 & 1.5 & 5.8 \\
Maximum & 44.0 & 46.0 & 42.0 & 40.0 & 38.0 & 24.0 \\
Coeff var & 41.5 & 30.1 & 28.5 & 26.6 & 50.4 & 46.0 \\
\hline
\end{tabular}

$\mathrm{R}=$ right side

$\mathrm{L}=$ left side 


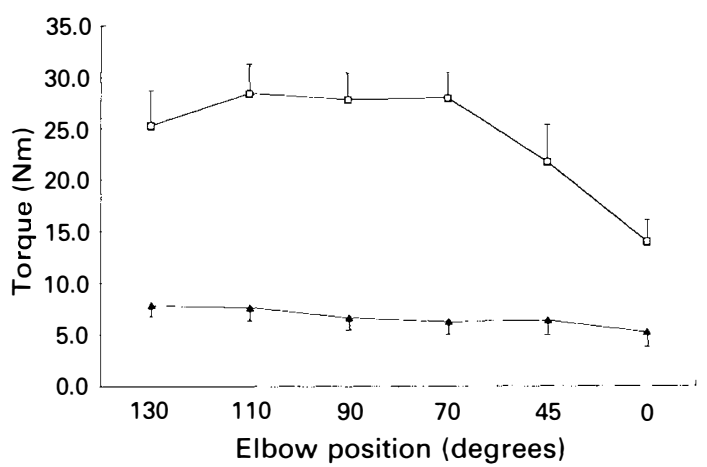

Figure 2 Absolute isometric torque output expressed as a function of elbow position, ie muscle length. White squares represent performances for the able bodied group plus one standard error. Black triangles represent performances for the quadriplegic group minus one standard error.

$r^{2}=0.95$, where Ep was the elbow position, ie the triceps length. In this case, ANOVA revealed homogeneous groups at 90 and $70^{\circ}$ (Table III) with significant statistical differ- ences but not for other muscle lengths $(p>0.1)$.

In a second experiment we studied the relation between performances and time before surgery (Fig 4). When patient 7 was excluded (a very long time before surgery) there appeared a relative relation where the linear regression gave the best result: $\mathrm{T}=0.3 \mathrm{~T}_{\mathrm{bs}}+3.51$, with $p=0.03, r=0.67$, where $T$ was the torque expressed in $\mathrm{Nm}$ and $T_{b s}$ was the time before surgery expressed in months. Nevertheless, the link between the two variables was not extremely strong $(r=0.67)$. In fact, 3 patients waited for 14 months before surgery (patients 4,6 and 5 right side) with different results after surgery - between 3.4 and $7.3 \mathrm{Nm}$. Moreover, patient 5 had very different results between sides for absolute values 14.6 and $7.3 \mathrm{Nm}$. Therefore, this difference must be due to the surgeon's technique. Concerning the performances expressed as a function of time after surgery, ie the rehabilitation time, we did not

Table IV Relative isometric torque output expressed as a percentage of maximum values at the different muscle lengths for the patients

\begin{tabular}{lrrrrrr}
\hline & & \multicolumn{5}{c}{ Elbow position (degrees) } \\
& 130 & 110 & 90 & 70 & 45 & 0 \\
\hline $1 \mathrm{R}$ & 100.0 & 60.0 & 46.7 & 33.2 & 26.6 & 26.6 \\
$1 \mathrm{~L}$ & 100.0 & 78.6 & 57.1 & 57.1 & 35.6 & 28.5 \\
$2 \mathrm{~L}$ & 51.9 & 51.9 & 55.5 & 85.0 & 100.0 & 74.1 \\
$3 \mathrm{R}$ & 86.5 & 100.0 & 81.1 & 70.2 & 64.8 & 45.9 \\
$3 \mathrm{~L}$ & 100.0 & 82.1 & 76.8 & 67.8 & 50.0 & 32.1 \\
$4 \mathrm{R}$ & 100.0 & 80.1 & 49.9 & 39.9 & 29.9 & 9.9 \\
$5 \mathrm{R}$ & 100.0 & 79.9 & 79.9 & 100.0 & 86.7 & 86.7 \\
$5 \mathrm{~L}$ & 43.3 & 50.0 & 50.0 & 56.6 & 93.3 & 100.0 \\
$6 \mathrm{~L}$ & 100.0 & 85.6 & 57.1 & 28.5 & 28.5 & 28.5 \\
$7 \mathrm{~L}$ & 74.9 & 100.0 & 68.7 & 37.5 & 49.9 & 5.8 \\
$8 \mathrm{R}$ & 77.2 & 100.0 & 95.5 & 72.8 & 72.8 & 77.2 \\
Average & 84.9 & 78.9 & 65.3 & 59.0 & 58.0 & 46.9 \\
SD & 20.9 & 18.2 & 16.0 & 22.8 & 27.2 & 32.3 \\
Std Er & 6.3 & 5.5 & 4.8 & 6.9 & 8.2 & 9.7 \\
Minimum & 43.3 & 50.0 & 46.7 & 28.5 & 26.6 & 5.8 \\
Maximum & 100.0 & 100.0 & 95.5 & 100.0 & 100.0 & 100.0 \\
Coeff var & 24.6 & 23.1 & 24.5 & 38.6 & 46.8 & 68.9 \\
ANOVA & 0.57 & 0.1 & 0.001 & 0.001 & 0.12 & 0.89
\end{tabular}

ANOVA $=$ One-way analysis of variance (expressive the $p$ values when relative values of torque were compared between groups) 


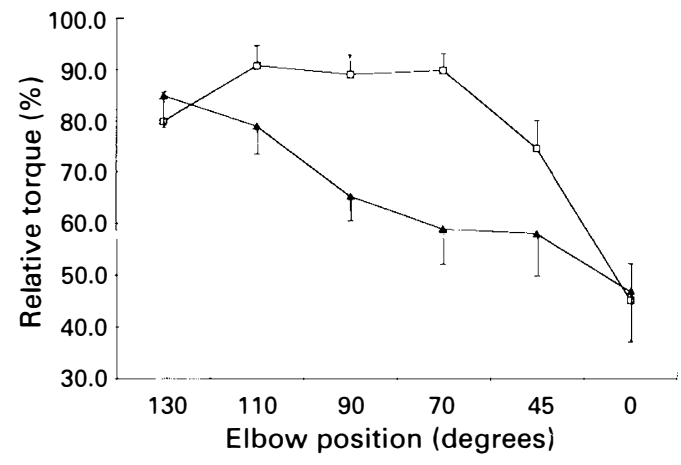

Figure 3 Relative values of isometric torque output for the able bodied group (white squares plus one standard error) and for the patients' group (black triangles minus one standard error) expressed as a function of elbow position.

find a true relation (Fig 5). It seemed that the results depended on the surgery.

\section{Discussion}

Different surgical techniques gave different results, as confirmed by another study ${ }^{5}$ in which comparable methods of assessment were used. Results were different for both absolute and relative values; maximal values were reported between 30 and $90^{\circ}\left(130^{\circ}\right.$ in the present study), and mean torque was $3.64 \mathrm{Nm}$ (between 5.2 and $7.8 \mathrm{Nm}$ in our

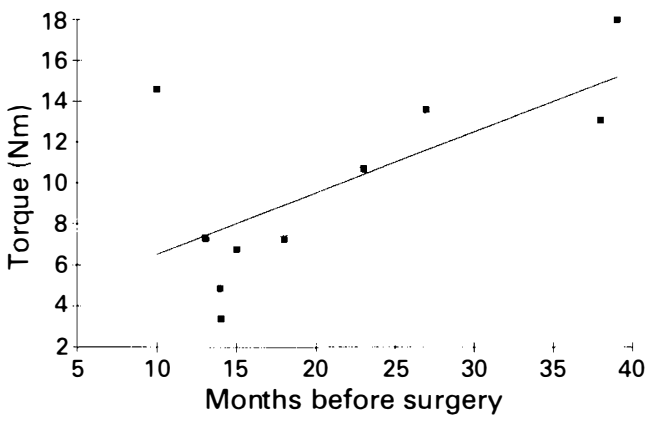

Figure 4 Torque output expressed as a function of time before surgery (in months) when patient 7 was excluded. Solid line represented the linear regression (explained in the text).

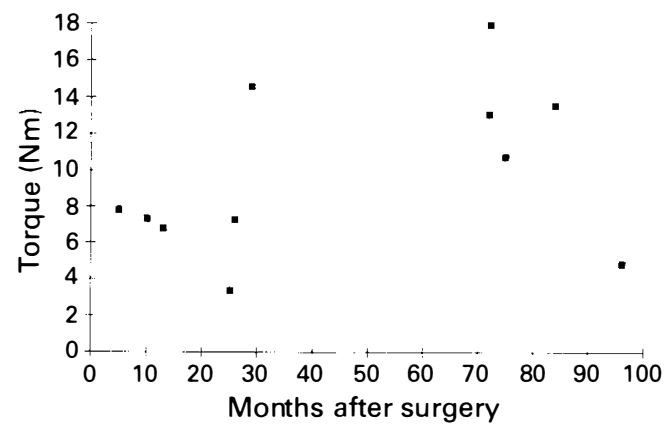

Figure 5 Torque output expressed as a function of time after surgery (in months).

Table V Relative isometric torque output expressed as a percentage of maximum values at the different muscle lengths for the able bodied group

\begin{tabular}{lrrrrrc}
\hline & \multicolumn{5}{c}{ Elbow position (degrees) } \\
\cline { 1 - 5 } & 130 & 110 & 90 & \multicolumn{1}{c}{70} & 45 & 0 \\
\hline 1 L & 60.0 & 100.0 & 93.0 & 100.0 & 86.7 & 53.3 \\
3 R & 95.7 & 100.0 & 91.3 & 87.0 & 82.6 & 43.5 \\
$4 \mathrm{R}$ & 100.0 & 78.1 & 90.3 & 90.3 & 82.9 & 46.3 \\
$5 \mathrm{R}$ & 73.5 & 82.4 & 92.1 & 100.0 & 82.4 & 48.5 \\
$6 \mathrm{R}$ & 53.8 & 69.2 & 84.6 & 84.6 & 100.0 & 92.3 \\
$7 \mathrm{R}$ & 76.5 & 94.1 & 88.2 & 100.0 & 64.7 & 47.1 \\
$8 \mathrm{R}$ & 89.3 & 100.0 & 100.0 & 71.4 & 46.4 & 21.4 \\
$9 \mathrm{R}$ & 70.0 & 96.7 & 100.0 & 93.4 & 66.6 & 23.3 \\
Average & 100.0 & 96.6 & 62.1 & 82.7 & 58.6 & 31.0 \\
SD & 79.9 & 90.8 & 89.1 & 89.9 & 74.5 & 45.2 \\
Std Er & 17.2 & 11.4 & 11.3 & 9.7 & 16.6 & 21.1 \\
Minimum & 5.7 & 3.8 & 3.8 & 3.2 & 5.5 & 7.0 \\
Maximum & 53.8 & 69.2 & 62.1 & 71.4 & 46.4 & 21.4 \\
Coeff var & 100.0 & 100.0 & 100.0 & 100.0 & 100.0 & 92.3 \\
\hline
\end{tabular}


study). The authors emphasised the useful length-tension relationship of the transfer due to their technique, where the transfer was not fully stretched with the elbow only partially extended with a flexion of $90^{\circ}$. We agree with this position even if the results obtained in the present study were functionally satisfying for the patient; quantitatively isometric torque output was superior in the range of motion described.

Results were difficult to compare with other data. ${ }^{6}$ In fact, the author assessed isotonic elbow extension using weight and pulley where the resistance (average $2.1 \mathrm{Kg}$, ranged from 0.45 to $4.1 \mathrm{Kg}$ ) was not constant in the range of motion explored and the arrival position was not described. The speed was not reported, therefore power could not be extracted from the data. On the other hand, pre and postoperative muscle tests were based on clinical testing. As the length-tension relationship of the transfer differed from normal triceps we assumed that the classic clinical test had to be adapted. Moreover, if gravity represented a known and defined force, the resistance applied by the clinician had a personal dimension. Therefore, results had to be precisely measured with a torque dimension. Nevertheless, if objective benefit could be quantified, the functional gain represented an individual variable certainly related to the patient's motivation.

Lower isometric torque output of the transplant seemed quite normal, according to the surface of the transfer, compared to one of a normal triceps. However, an important feature has to be emphasised. Maximal output was recorded, on average, at $130^{\circ}$ of elbow flexion in patients, ie at the longest transfer length. Physiologically, maximum output was usually delivered at the middle of the muscle range of motion. Therefore, the transfer appeared to be longer than normal triceps even though it was fully stretched at the end of the surgery. As mentioned before, rehabilitation has to restore the full range of motion, and to actively stretch the transfer. In such conditions to reach $130^{\circ}$ of elbow flexion implied length changes. Dacron was stiffer than the transfer, therefore the gain in length was possible at the level of the sutures and within the muscle. Thus, the muscle was adapting its length to reach a new functional length.

Our patients had a lack of active extension of about $15^{\circ}$, that has been confirmed by other authors. ${ }^{7}$ The time before surgery seemed to be an important variable. The lowest results were obtained between 13 and 20 months with an exception (patient 5, left side). The best delay appeared to be between 23 and 39 months. Longer time (patient 7) made the prediction difficult, a fact confirmed by other authors. ${ }^{8}$ Therefore, the preparation of the transfer required time to be effective.

Functionally, the benefit was evident in all patients: improved ability to propel the wheelchair, to catch objects overhead, to turn in bed and to swim.

\section{References}

1 Moberg E (1975) Surgical treatment for absent single-hand grip and elbow extension in quadriplegia, J Bone Joint Surg 57 A: 196-206.

2 Allieu Y, Benichou M (1992) Chirurgie fonctionelle du membre supérieur de tétraplégique. Etat actuel. Refléxions à propos de 10 ans d'expérience. Proceedings Les Journées de PROPARA, Montpellier, 55-82.

3 Johnstone BR, Jordan CJ, Buntime JA (1988) A review of surgical rehabilitation of the upper limb in quadriplegia. Paraplegia 26: 317-39.

4 Rabischong E, Ohanna $F()$ Effects of functional electrical stimulation (FES) on evoked muscular output in paraplegics' quadriceps muscle. Paraplegia 30: 467-473.

5 Lacey SH, Wilber GW, Peckam PH, Freehafer AA (1986) The posterior deltoid to triceps transfer: A clinical and biomechanical assessment. J Hand Surg 11A: 542-7.

6 Debenedetti M (1979) Restoration of elbow extension power in the tetraplegic patient using Moberg technique. J Hand Surg 4: 86-9.

7 Lamb DW, Chan KM (1983) Surgical reconstruction of the upper limb in traumatic paraplegia. A review of 41 patients. J Bone Joint Surg 8B: 119-31.

8 Hentz VR, Brown M, Keoshian LA (1983) Upper limb reconstruction in quadriplegia: Functional assessment and proposed treatment modifications. J Hand Surgery 8: 119-131. 